\title{
L'AULA DE CINEMA DE LA UNIVERSITAT D'ALACANT
}

Israel GIL PÉREZ

Universitat d'Alacant

Que no hi haja ni un sol cinèfil desatès. $O$ aficionat al cinema, hauríem de dir, tenint en compte les connotacions negatives que se li dóna, des de fa algun temps, a la paraula cinèfil. Aquest ha de ser el propòsit de l'Aula de Cinema de la Universitat d'Alacant. Que alumnes, professors, la resta de la comunitat universitària i també la comunitat no universitària troben activitats relacionades amb el setè art que satisfacen la seua inquietud cultural i completen la seua formació acadèmica.

Ningú dubta, en l'era dels crèdits de lliure elecció, de la responsabilitat de les universitats modernes d'atorgar una formació completa als estudiants. I l'Aula de Cinema del Secretariat de Cultura, depenent del Vicerectorat d'Extensió Universitària, l'assumeix amb una oferta clara d'activitats relacionades amb la música, el teatre, la literatura, la dansa, el còmic, les arts en general i, per descomptat, amb el cinema, i demostra, d'aquesta manera, que s'arriba a l'educació integral gràcies, també, a les arts i la cultura.

Sempre hem de partir de les pel-lícules. Són el cinema i sense aquestes no hi ha cinema. Per descomptat que es pot fer un seminari sobre el cinema com a mitjà de comunicació, o sobre les lents de les càmeres de Chaplin o sobre els orígens de l'Institut Cubà de les Arts i les Ciències Cinematogràfiques, i que cap dels ponents esmente en les seues intervencions una sola pel-lícula. Però poques activitats (i, a més, una mica òrfenes) podrà oferir un Aula de Cinema que no tinga una filmoteca nodrida i que es trobe al servei de la comunitat universitària. La filmoteca de la Universitat d'Alacant, malgrat la seua joventut i que els recursos puguen ser limitats, disposa ja d'un fons amb més de tres mil títols, en format DVD i també VHS, aquest últim quasi en desús però al qual hem de recórrer en algunes ocasions a l'espera de digitalitzacions de títols imprescindibles que només es troben en suport electromagnètic. Els formats domèstics permeten el préstec, sobretot, a professors i alumnes interessats en el cinema com a mitjà utilíssim per a il·lustrar les matèries que imparteixen o estudien. Per això les visites d'interessats que acudeixen a nosaltres és diària i cada vegada més exigent: “Alguna pel-lícula sobre la revolució russa?" "I sobre la gran depressió nord- 
americana?" "I sobre pingüins?" "I sobre la llei del jurat?" "Sobre el nombre pi?" "I sobre l'efecte dels llamps gamma sobre les margarides?" És el dia a dia d'un aula de cinema, d'un servei cada vegada més present a la Universitat d'Alacant.

Prestem les pel-lícules a professors o alumnes que les utilitzen amb una finalitat educativa, acadèmica. Per a il-lustrar una classe, per a investigar, perquè una imatge (de vegades) val més que mil paraules. Però advertim als usuaris que el cinema ha de ser una experiència col-lectiva. Que sempre és millor que una pluralitat de persones se submergisca en la sala fosca per a gaudir, al mateix temps, de les pel-lícules. I per a parlar-ne abans i després. I per això oferim a la comunitat universitària una sala perfectament equipada per al visionat. Des del curs 2005-2006 la filmoteca i la sala de projeccions es troben a la Sala Aifos, situada a la planta baixa de l'edifici C de Filosofia i Lletres, la facultat veïna que inicialment va acaparar la major part de les sol-licituds. Amb el temps han recorregut a nosaltres docents i investigadors de diferents àrees del campus. El cinema ha deixat de ser patrimoni de les lletres per a ser també una realitat en els estudis de ciències experimentals, socials, jurídiques i un llarg etcètera fins a completar el mosaic divers dels nostres centres. A la sala de projeccions Aifos les butaques són còmodes però no conviden a la son. La nostra pantalla no és, ni falta que fa, de la dimensió descomunal de les dels centres comercials i el nostre so "envolta" però sense deixar-nos sords. Però és que no volem que ningú s'adorma ni que s'aclapare amb els efectes especials o sonors. És una sala magnífica per al gaudi de qualsevol pel-lícula, que ha sigut utilitzada per tants professors i de departaments tan dispars que quasi podem assegurar que molt pocs en desconeixen l'existència; més de quatre-centes projeccions anuals n'avalen l'interès i la raó de ser.

A més, l'Extensió Universitària, creada fa ja més de cent anys en l'acord del Claustre de Dret de la Universitat d'Oviedo en el qual Leopoldo Alas arreplegava la idea expressada per l'alacantí Rafael Altamira en el discurs inaugural del curs 18981899, i de la qual la Universitat d'Alacant és capdavantera amb un vicerectorat ad hoc ens obliga (o ens convida, hauríem de dir), a organitzar cicles de cinema, seminaris i cursos en totes les localitats que es van constituir en seu de la Universitat d'Alacant. Així, han gaudit de Billy Wilder a Biar, de Tourneur a Villena, de Rossellini a la Nucia, de Hitchcock a Xixona, dels germans Lumière a Benissa...i l'etcètera és llarguíssim. També va haver-hi pel-lícules sobre ciència i tecnologia durant Cienciatec, les denominades "pel-lícules de judicis" en la Setmana Cultural de la Facultat de Dret... 
Triem el Centre 14, edifici cultural situat al barri antic d'Alacant, per als nostres cicles en versió original. Bergman, el càrrec de consciència en el cinema, Woody Allen en blanc i negre, el cinema dins del cinema, Atom Egoyan, la pena de mort en el cinema i, sobretot, el cicle dedicat a Murnau, en el qual va haver-hi una sessió de la seua pel-lícula muda L'últim, amb acompanyament musical en directe a càrrec del grup Ensamble, conduït pel pianista portuguès Arsénio Martins, que han fet les delícies dels sectors més rigorosos i exigents. Un dels assistents a aquest últim esdeveniment, de 91 anys, va assegurar haver assistit a l'estrena de la pel-lícula a Berlín al desembre de 1924, acompanyat pel seu pare, que treballava per a la UFA (Universum Film Aktiengesellschaft).

A la Seu d'Alacant hem programat monogràfics de l'etapa nord-americana de Fritz Lang, pel-lícules amb el mar Mediterrani com a protagonista, cinema negre (sempre al maig) i, per Nadal, de Buster Keaton, dels germans Marx i de Chaplin. Pel-lícules per a tota la família. Les nostres enquestes sobre les activitats que podríem dur a terme i sobre els aspectes positius o susceptibles de canvis de cadascuna de les que fem són la guia que ens condueix a una millora progressiva dels nostres serveis. Amb intencions semblants, en el curs 2005-2006 el Vicerectorat d'Extensió Universitària va constituir la Comissió Assessora de l'Aula de Cinema, formada per més de trenta professors que participen directament en les propostes que portem endavant. Un exemple que ara es concreta n'és la nova revista Quaderns de Cine, una aposta decidida per la difusió del setè art a la nostra Universitat, caracteritzada per l'ús de les noves tecnologies en l'àmbit de la investigació i de la docència.

Per als qui no es conformen amb el visionat de pel-lícules, per als qui volen aprofundir en teoria, tècnica, estils, oferim els nostres cursos i tallers. Cada quadrimestre el Secretariat de Cultura ofereix una mitjana de deu cursos o tallers que tenen el cinema com a protagonista principal. El muntatge, el guió i la música, d'una banda, o el gènere documental, els corrents cinematogràfics europees i els mestres del Hollywood clàssic, d'una altra, s'han estudiat detalladament en una universitat que, per mancar, fins al moment, d'estudis superiors de cinema o comunicació audiovisual, requereix professors preparats que cobrisquen les inquietuds i els currículums dels alumnes de la Universitat. El nostre "Mostrari” (Mostra de Documental Universitari Europeu), el Seminari de Cinema i Literatura o les Jornades de Doblatge i Subtitulació són activitats que organitzem o en les quals col-laborem i que tenen diverses edicions a les espatles, prova de la consolidació i l'interès de les nostres propostes. 
Altres departaments de la Universitat treballen en l'audiovisual, com el Taller Digital o el Taller d'Imatge, però amb comeses distintes. El primer, segons la seua web, "naix l'any 2004 com a empresa de base tecnològica per a la producció de continguts digitals en múltiples formats, desenvolupaments d'eines i entorns informàtics i anàlisis de demandes dels continguts en la xarxa, a més de les activitats relacionades amb el disseny, el màrqueting i el posicionament per a Internet". El Taller d'Imatge de la Universitat d'Alacant naix el 1988 com a projecte d'investigació. Des de llavors ha fet una labor continuada tant de formació de professionals en el món de la imatge com de producció audiovisual en la mateixa Universitat i fora d'aquesta. Des del 2006 resideix en la Fundació General de la Universitat d'Alacant.

Per contra, l'Aula de Cinema ha tingut des dels seus orígens unes comeses més concretes, centrades en el suport a la docència i a la investigació. "Va començar a funcionar el curs 1984-1985 després de la subscripció d'un acord de col-laboració entre el Vicerectorat d'Alumnat i Extensió Universitària i el Cine-Club Mediterráneo de la CAM. Es va crear amb l'objectiu d'acostar l'alumne universitari a la cultura cinematogràfica i utilitzar aquest mitjà com un sistema més de suport a l'activitat docent i investigadora". Encara es pot llegir aquest text en la web de la Universitat d'Alacant. Han passat molts anys, però l'Aula de Cinema continua, i continuarà, donant suport als cinèfils (aficionats al cinema) als quals ens devem. Esperem estar a la vostra altura. 